\title{
Commentary: Selection criteria for valvular prostheses: Are we just scratching the surface?
}

\author{
Alan M. Speir, MD \\ From the Inova Heart and Vascular Institute, Falls Church, Va. \\ Disclosures: Author has nothing to disclose with regard to commercial support. \\ Received for publication Feb 26, 2019; accepted for publication Feb 26, 2019; available ahead of print April 11, \\ 2019. \\ Address for reprints: Alan M. Speir, MD, Inova Heart and Vascular Institute, 3300 Gallows Rd, Falls Church, VA \\ 22042 (E-mail: alan.speir@inova.org). \\ J Thorac Cardiovasc Surg 2020;159:100-1 \\ 0022-5223/\$36.00 \\ Copyright (c) 2019 by The American Association for Thoracic Surgery \\ https://doi.org/10.1016/j.jtcvs.2019.02.100
}

The criteria for selection of a particular prosthetic heart valve may be quite complex, far more so that might appear on surface examination. Such criteria might be subjective with weight given to the historical perspective of valve type and implantation philosophy of the institution where the surgeon trained, information from the local manufacturer's representative, or convincing arguments by the surgeon's partners or colleagues. Alternatively, criteria may be more weighted from available clinical data with published outcomes of mortality, rates of thromboembolism, effective orifice area, mean and peak gradients, left ventricular mass regression, data presented from a particularly influential conference or seminar, or the cost of the different devices.

As time has allowed more biomedical engineering evaluation techniques to evolve, more precise and exacting scientific methods for prosthetic analyses have been developed and applied that may affect such selection criteria. The article by Hatoum and colleagues, ${ }^{1}$ published in this issue of the Journal, is a significant deviation from the prior customary approaches for such prosthetic valve investigation. Their examinations, using highly sophisticated biomedical engineering techniques, reveal a whole different perspective of performance between the 2 commonly implanted mechanical prostheses that might not otherwise appear obvious on the surface.

Consider, for example, the contrast in design between the 2 valves. The ON-X mechanical prosthesis (Cryolife Inc, Kennesaw, Ga) has a flared inlet compared with the SJM (St Jude Medical, St Paul, Minn), in addition to the larger inlet diameter (21.3-mm ON-X compared with $18.6-\mathrm{mm}$ SJM) for the same valve size $(23 \mathrm{~mm})$. The resultant effective orifice area was expectantly larger in the $\mathrm{ON}-\mathrm{X}$ valve than in the SJM valve for the stated size, a perceived relevant advantage for the $\mathrm{ON}-\mathrm{X}$ prosthesis. However, Hatoum and colleagues ${ }^{1}$ calculated what they termed the "area index" (the nondimensional index) to measure the valve's resistance characteristics independent of the valve size.

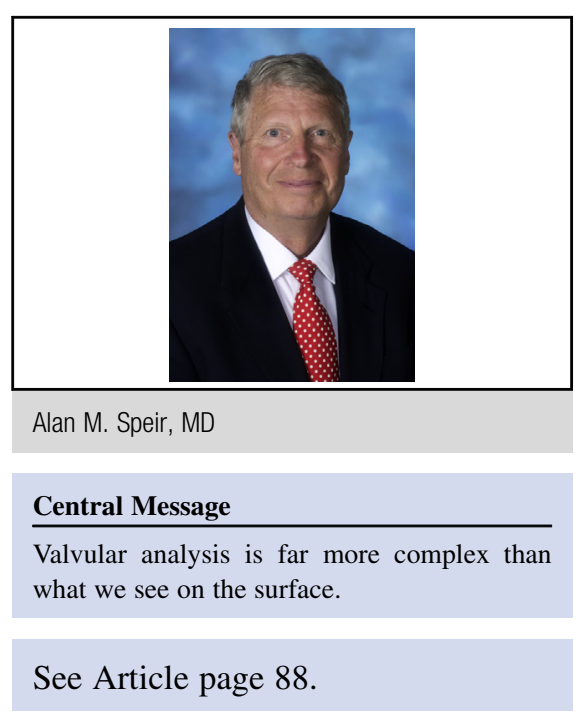

This area index, derived as the effective orifice area of both valves divided by the internal geometric area, demonstrates how well each valve design uses its total orifice area. The area index of the $\mathrm{ON}-\mathrm{X}$ was calculated to be $0.73 \pm 0.013$ versus $0.87 \pm 0.008$ for the $\operatorname{SJM}(P<.001)$. It is clear that the SJM better uses its total orifice area compared with the ON-X. In other words, the extra area of the ON-X is not fully used to provide an advantage over SJM.

An additional measurement was the velocity in the lesser orifice of the 2 valves. "The SJM exhibits higher velocities at the middle jet compared with the ON-X starting from $2.32 \mathrm{~m} / \mathrm{s}$ and ending at $\mathrm{x}=30 \mathrm{~mm}$ with a velocity of $1.73 \mathrm{~m} / \mathrm{s}(0.59 \mathrm{~m} / \mathrm{s}$ difference $)$. While for the ON-X, the velocity at the opening was shown to be $1.85 \mathrm{~m} / \mathrm{s}$ and at $\mathrm{x}=30 \mathrm{~mm}, 1.42 \mathrm{~m} / \mathrm{s}(0.43 \mathrm{~m} / \mathrm{s}$ difference $) .{ }^{, 1}$ Despite the lower velocities in the $\mathrm{ON}-\mathrm{X}$ valve, there were higher levels of turbulence, which in this context is characterized by high irregularities, diffusion, and dissipation of kinetic energy, among others, that not only damage blood cells but also increase pressure losses.

Furthermore, in the leaflet tracking results, it was noted that the larger leaflets of the ON-X demonstrated more leaflet flutter compared with the SJM that shows a relatively more stable leaflet behavior throughout the cardiac cycle due to the smaller leaflets. Hatoum and colleagues ${ }^{1}$ postulated that the larger the leaflets, the harder it is to maintain a stable leaflet behavior under the measured flow 
conditions. In addition, the incomplete leaflet opening of the SJM leaflets allows the fluid pressure force to keep the leaflet pressed open against the hinge with resultant improved stability. Further analysis will be required to determine the clinical relevance of such an observation.

This article demands more attention to detail and clearly is more challenging in its understanding for those readers who may not have bioengineering or biomedical backgrounds. The effort is well worth it, because such information and perspective expand our level of knowledge well beyond the usual decision algorithm for those willing to "scratch the surface" of existing valve information.

\section{Reference}

1. Hatoum H, Maureira P, Dasi L. A turbulence in vitro assessment of On-X and St Jude Medical prostheses. J Thorac Cardiovasc Surg. 2020;159:88-97. 